\title{
INTERVALO HÍDRICO ÓTIMO UTILIZANDO DIFERENTES PLANTAS DE COBERTURA E SISTEMAS DE PREPARO DE SOLO
}

\section{Eduardo Belarmino da Silva, Zigomar Menezes de Souza, Ingrid N. de Oliveira, Lenon Henrique Lovera, Elizeu de S. Lima, Christtiane F. Oliveira, Maria Cecília V. Totti, Diego Alexander A. Esteban, Jeison S. Parra, Marina Pedroso}

\section{Resumo}

No Brasil, há uma tendência de aumento da mecanização em campo e utilização de preparos conservacionistas. Com isto, o objetivo deste trabalho foi avaliar o intervalo hídrico ótimo ao longo do ciclo de produção da cana-de-açúcar com diferentes plantas de cobertura e sistemas de preparo do solo. O estudo foi conduzido em condições de campo, na usina Santa Fé, localizada no município de Ibitinga-SP. Foram utilizadas quatro plantas de cobertura (crotalária, milheto, amendoim e sorgo) e três sistemas de preparo de solo (plantio direto, cultivo mínimo e cultivo mínimo com subsolagem profunda). O milheto e a crotalária, melhoram a estrutura do solo e o teor de água no solo. $O$ preparo convencional proporcionou menor teor de água no solo, maior densidade do solo e, portanto, menor intervalo hídrico ótimo.

Palavras-chave: Plantio direto, cultivo mínimo, compactação do solo, teor de água no solo.

\section{Introdução}

O plantio direto, que preza pelo não revolvimento do solo, utilização de plantas de cobertura e a manutenção do solo coberto geram a manutenção de teores de água no solo adequado em sistemas que utilizam plantas de cobertura e sistemas de preparo do solo conservacionistas. O manejo do solo em plantio direto ainda não está totalmente compreendido, principalmente em áreas de cana-de-açúcar. Dessa forma, o intervalo hídrico ótimo (IHO) se mostra como uma das formas de análise de diversos atributos do solo.

\section{Resultados e Discussão}

Houve diferença entre os valores de resistência do solo à penetração (Tabela 1) apenas no primeiro ciclo da canade-açúcar, onde houve maior efeito dos preparos do solo, principalmente no tratamento com plantio direto que obteve maiores valores em ambas camadas.

Devido as altas densidades do solo, ocorreu um pequeno $\mathrm{IHO}$, principalmente na camada subsuperficial (Figuras 1 e 2). Estreitos valores do $\mathrm{IHO}$ indicam que as culturas podem ser submetidas a restrições por aeração deficiente ou excessiva impedância mecânica durante o seu crescimento.

Tabela 1. Resistência do solo à penetração (MPa) na tensão de $6 \mathrm{kPa}$ para um Argissolo Vermelho com diferentes plantas de cobertura e preparos de solo.

\begin{tabular}{|c|c|c|c|c|c|c|c|c|}
\hline \multirow{2}{*}{ Tratamento } & \multicolumn{4}{|c|}{$2015 / 2016$} & \multicolumn{4}{|c|}{$2016 / 2017$} \\
\hline & $\mathrm{CM}$ & PD & SP & Média & $\mathrm{CM}$ & $\mathrm{PD}$ & SP & Média \\
\hline \multicolumn{9}{|c|}{$0,00-0,15 \mathrm{~m}$} \\
\hline Amendoim & $0,97 \mathrm{bB}^{*}$ & $1,88 \mathrm{aA}$ & $0,57 \mathrm{bB} *$ & $1,14 \mathrm{a}$ & 1,3 & 1,03 & 0,95 & $1,09 \mathrm{a}$ \\
\hline Crotalária & $1,07 \mathrm{abA}^{*}$ & $1,09 \mathrm{bA}^{*}$ & $1,4 \mathrm{aA}$ & $1,18 \mathrm{a}$ & 1,78 & 1,06 & 1,68 & $1,51 \mathrm{a}$ \\
\hline Milheto & $0,79 \mathrm{bC} \mathrm{b}^{*}$ & $1,74 \mathrm{aA}$ & $1,25 \mathrm{aB}$ & $1,26 \mathrm{a}$ & 1,64 & 1,22 & 0,83 & $1,23 \mathrm{a}$ \\
\hline Sorgo & $1,43 \mathrm{aA}$ & $1,47 \mathrm{abA}$ & $0,65 \mathrm{bB}^{*}$ & $1,18 \mathrm{a}$ & 1,69 & 1,58 & 1,78 & $1,68 \mathrm{a}$ \\
\hline Média & $1,07 \mathrm{~B}$ & $1,54 \mathrm{~A}$ & $0,97 \mathrm{~B}$ & & $1,60 \mathrm{~A}$ & $1,22 \mathrm{~B}$ & $1,31 \mathrm{AB}$ & \\
\hline Testemunha & \multicolumn{4}{|c|}{1,56} & \multicolumn{4}{|c|}{1,54} \\
\hline \multicolumn{9}{|c|}{$0,15-0,30 \mathrm{~m}$} \\
\hline Amendoim & $1,17 \mathrm{bA}$ & $1,45 \mathrm{aA}$ & $1,09 \mathrm{abB}$ & $1,24 \mathrm{~b}$ & 1,36 & 1,25 & 0,84 & $1,15 \mathrm{a}$ \\
\hline Crotalária & $2,14 \mathrm{aA}^{*}$ & $1,4 \mathrm{aB}$ & $1,39 \mathrm{aB}$ & $1,64 \mathrm{a}$ & 1,48 & 1,02 & 1,06 & $1,19 \mathrm{a}$ \\
\hline Milheto & $1,23 \mathrm{bA}$ & $1,52 \mathrm{aA}$ & $1,16 \mathrm{abA}$ & $1,30 \mathrm{ab}$ & 1,66 & 1,22 & 1,28 & $1,39 \mathrm{a}$ \\
\hline Sorgo & $1,42 \mathrm{bA}$ & $1,58 \mathrm{aA}$ & $0,69 \mathrm{bB} *$ & $1,23 \mathrm{~b}$ & 1,76 & 1,5 & 1,54 & $1,60 \mathrm{a}$ \\
\hline Média & $1,49 \mathrm{~A}$ & $1,49 \mathrm{~A}$ & $1,08 \mathrm{~B}$ & & $1,57 \mathrm{~A}$ & $1,25 \mathrm{~B}$ & $1,18 \mathrm{~B}$ & \\
\hline Testemunha & \multicolumn{4}{|c|}{1,5} & \multicolumn{4}{|c|}{1,85} \\
\hline
\end{tabular}

$\mathrm{PD}=$ plantio direto, $\mathrm{CM}=$ cultivo mínimo, $\mathrm{CM} / \mathrm{SP}=$ cultivo mínimo com subsolagem profunda.
(A)
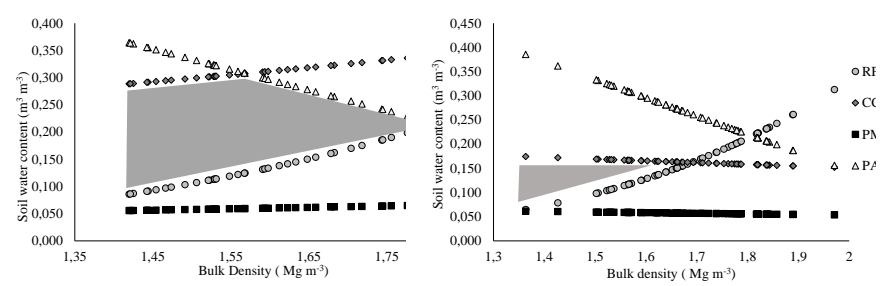

Figura 1. Teor de água do solo em relação com a densidade do solo (Ds) sob cana-de-açúcar em níveis críticos de capacidade de campo $(\mathrm{CC}=-33 \mathrm{kPa}$ ), ponto de murcha permanente (PMP $=-1.500 \mathrm{kPa})$, porosidade de aeração $\left(\mathrm{PA}=0,10 \mathrm{~m}^{3} \mathrm{~m}^{-3}\right) \mathrm{e}$ resistência do solo à penetração $(\mathrm{RP}=-2.000 \mathrm{kPa})$. A área rachurada representa o intervalo hídrico ótimo, nas profundidades de 0,00-0,15 m (A) e 0,15-0,30 m (B).

(A)

(B)

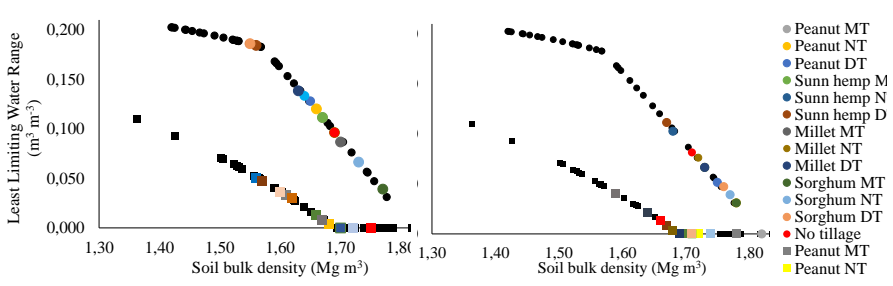

Figura 2. Intervalo hídrico ótimo em área do canavial para as camadas de 0,00-0,15 m e 0,15-0,30 m. (A) - Cana planta (ciclo 2015/2016); (B) - Cana soca (ciclo 2016/2017).

\section{Conclusões}

Os sistemas de preparos do solo conservacionistas, como o cultivo mínimo e plantas de cobertura aumentam os intervalos hídricos do solo comparado ao sistema convencional.

\section{Agradecimentos}

Os autores agradecem a Fundação Agrisus (Proj. 1439/15) pelo financiamento, ao CNPq pela bolsa de mestrado (130826/2017-0) e ao Pibic pela bolsa de IC concedida. 